\title{
Morphological Evaluation of Surface Degradation and Mechanical Properties of Compressed-Earth Blocks (CEB)
}

\author{
A. Martínez Loaiza ${ }^{1}$, J. F. Pérez-Sánchez ${ }^{2}$, E. J. Suárez-Domínguez ${ }^{2, *}$, M. T. Sánchez-Medrano², \\ V. M. García Izaguirre ${ }^{2}$ A. Palacio-Pérez ${ }^{3}$ \\ ${ }^{1}$ Engineering Faculty, UAT. Tampico, Tamaulipas, México \\ ${ }^{2}$ Faculty of Architecture and Urbanism, UAT, Tampico, Tamaulipas, México \\ ${ }^{3}$ Engineering Institute, UNAM, Ciudad de México, México
}

Received March 21, 2021; Revised April 12, 2021; Accepted May 28, 2021

\section{Cite This Paper in the following Citation Styles}

(a): [1] A. Martínez Loaiza, J. F. Pérez-Sánchez, E. J. Suárez-Domínguez, M. T. Sánchez-Medrano, V. M. García Izaguirre, A. Palacio-Pérez, "Morphological Evaluation of Surface Degradation and Mechanical Properties of Compressed-Earth Blocks (CEB)," Civil Engineering and Architecture, Vol. 9, No. 4, pp. 992 - 998, 2021. DOI: 10.13189/cea.2021.090403.

(b): A. Martínez Loaiza, J. F. Pérez-Sánchez, E. J. Suárez-Domínguez, M. T. Sánchez-Medrano, V. M. García Izaguirre, A. Palacio-Pérez (2021). Morphological Evaluation of Surface Degradation and Mechanical Properties of Compressed-Earth Blocks (CEB). Civil Engineering and Architecture, 9(4), 992 - 998. DOI: 10.13189/cea.2021.090403.

Copyright@ 2021 by authors, all rights reserved. Authors agree that this article remains permanently open access under the terms of the Creative Commons Attribution License 4.0 International License

\begin{abstract}
Earth architecture has been an ecological alternative since the surrounding materials can be used. The durability of earth elements such as compressed-earth blocks (a soil brick) is less than that of traditional blocks. In the present work, the evaluation of weathered earth-based walls was carried out after six years in the mid-region of the Gulf of Mexico coast (Tampico, Tamaulipas, Mexico) and contrasted with sections of compressed earth block without environmental degradation. The blocks were fabricated from two different blends with the following materials: (A) $50.4 \%$ clay soil (Altamira, Tamaulipas, Mexico), 38.4\% Medrano sand, $6.4 \%$ cement, and $4.8 \%$ nopal mucilage aqueous solution (1:10). (B) $50 \%$ clay soil, $35 \%$ cement, $10 \%$ lime, and 5\% nopal mucilage aqueous solution. A stochastic model was developed from image analysis to understand the biofilm formation process, and the modification of the compressive strength was evaluated. It was found that the compressive strength decreases (up to $65 \%$ ) due to degradation. The CEBs stabilized with lime showed no surface changes, and there were no changes in the strength properties. For the cases in which there was degradation, it the fractal dimension and the respective specific surface area were found to have increased. This work can improve the perception of using this material in Mexico's regions, where the humidity levels are potentially
\end{abstract}

dangerous for the earthen structures. Besides, it offers a non-destructive methodology to determine the deterioration of housing walls built with earth elements.

Keywords Degradation of Compressed-Earth Blocks, Microbiota in Walls, Compressed-Earth Blocks Mechanical Properties

\section{Introduction}

Currently, earthen construction represents a feasible and economic possibility for implementing housing development [1,2]; however, Mexican people usually have a negative perception due to its nature.

In many regions of the country, there are limited economic resources, and it is not possible to perform proper maintenance of the walls in houses. Thus, microorganisms grow on the surface of the walls that are harmful to the users and damage the structure of the building walls [3]. Some techniques have been proposed for preserving earth-based materials that are not suitable for humid regions in Mexico [4].

Environmental degradation is commonly related to the 
mass lost on a surface by interaction with rain and microorganisms. The surface portion covered by the organisms and the average thickness of biofilm depends on their reproduction and metabolism. Besides, closed environments with high humidity and warm temperatures potentiate the growth of organisms. Therefore, the substrate plays a vital role because it can retain the nutrients and the moisture required for the survival of microbiome [5]. The presence of microorganism can reduce the mechanical properties of the earth elements due to the environmental Surface degradation or mass loss, changing the strength of the components $[6,7]$

The reproduction processes of microorganisms manifest themselves in the formation of random spatial patterns characterized by fractal geometry. Although some methods have been established in the durability of soil elements, it is necessary to carry out studies to recognize other effects[8]. Degradation is independent of other effects like drying that affect surface [9]. Once the blocks are in their final state with or without any additive or stabilizing component [10], the development of a biofilm can be quantified through direct observation of its thickness, which is practically impossible or expensive. It could require the breaking of the wall to observe a cross-section and evaluate the width of biofilm.

This work studied the surface change of compressed-earth blocks (CEB) with 6-year aging in the Gulf of Mexico coast (Tampico, Tamaulipas, Mexico). We contribute to the state to the art by giving the image analysis of the surfaces and applying a stochastic formalism along with fractal geometry described the dynamic growth behavior of microbiota on the wall of a house based on compressed earth block lack of maintenance and exposure to a high humidity ambient. The surface analysis results were contrasted with the compressive and flexural strengths of elements to correlate the presence of microorganisms with the mechanical properties.

\section{Methods}

For the experiment, ten elements exposed to moisture were sampled after six years. The CEBs were produced according to [11] for an A-group of the blend: $50.4 \%$ clay soil (Altamira, Tamaulipas, Mexico), 38.4\% Medrano sand, $6.4 \%$ cement, and $4.8 \%$ nopal mucilage aqueous solution (1:10). A B-group was manufactured from $50 \%$ clay soil, $35 \%$ cement, $10 \%$ lime, and $5 \%$ nopal mucilage aqueous solution (1:10). Ten elements of each blend were stored in a moisture-free ambient under controlled conditions for the same period.

Microbiome growth was photographed with a $640 \times 480$ digital microscope with 100x magnification for 28 pictures and the case of the exposed probes; 14 of them correspond to interior walls and 14 to exterior walls. The images were analyzed with the ImageJ software [12]. The average biofilm thickness was determined from the mean value of the intensity of the pixels divided by maximum brightness. In contrast, the value of the estimated thickness was determined using Equation (30). The conversion of 8-bit images to binary was carried out considering a pixel intensity threshold equal to 97 (Figure 3). The fractal dimension was determined for each of the binary images using the box-counting method.

The compressive strength was measured under the NMX-C-508-ONNCCE-2015 Mexican standard.

\section{A. Obtention of the stochastic model}

The model proposed was applied to determine the growth dynamics of microorganisms on the interior (with moisture) and exterior walls in low-income housing. The following criteria were considered: i) the extensive variable that describes the behavior of the biofilm is the number of clusters of microorganisms $N$ of average thickness $l$ that form a biofilm over a total surface A, where the individual cluster surface is $a_{0}$; ii) although there may be different species of microorganisms, a single virtual species will be considered whose dynamic behavior corresponds to the macroscopic behavior of the biofilm; iii) the intensive variable considered is the volume $\theta$ of the microorganisms per unit of surface, where the relationship between the intensive and extensive variables is:

$$
\theta=\frac{N v}{A}
$$

where $\mathrm{V}$ is the volume occupied by an individual conglomerate; iv) it is taken into account that the microscopic processes that take place are the reproduction of the microbiota, whose probability of transition per unit of time is established a priori as:

$$
W_{N+1 / N}=\mu N
$$

and the competition of the microorganisms for the available space, whose probability of transition is assumed as follows:

$$
W_{N-1 / N}=\frac{\beta v}{A} N^{2}
$$

where $\mu$ is the velocity constant associated with the reproduction of organisms and $\beta$ is the velocity constant related to their death. From the transition probabilities per unit of time [13] the master equation (ME) is obtained, which describes the behavior of the probability $\mathrm{P}(\mathrm{N} ; \mathrm{t})$ that there are $\mathrm{N}$ microorganisms at time $\mathrm{t}$ :

$$
\begin{gathered}
\frac{\partial P(N ; t)}{\partial t}=\left(E^{-1}-1\right) \mu N P(N ; t)+\left(E^{+1}-1\right) \beta N^{2} P(N ; t) \\
P\left(N_{0} ; 0\right)=1
\end{gathered}
$$

If the system is observed on the mesoscopic scale and the change $\Delta \mathrm{N}$ is negligible compared to $\mathrm{N}$, then $\mathrm{N}$ can be considered a continuous variable, and a Fokker-Planck differential equation is obtained for the ME: 


$$
\frac{\partial P(N ; t)}{\partial t}=-\frac{\partial}{\partial N}\left(\mu N-\beta N^{2}\right) P(N ; t)+\frac{1}{2} \frac{\partial^{2}}{\partial N^{2}}\left(\mu N+\beta N^{2}\right) P(N ; t)
$$

The mesoscopic model describes the evolution of the average thickness of the biofilm as a manifestation of the stochastic nature of the reproduction-death cycle. Then, Equation (6) is expressed as a function of the intensive variable that describes the system, considering that:

$$
\begin{gathered}
P(N ; t) \partial N=P(\theta ; t) \partial \theta \\
P(N ; t)=P(\theta ; t) \frac{\partial \theta}{\partial N}=P(\theta ; t) \frac{v}{A} \\
\frac{\partial P(\theta ; t)}{\partial t}=-\frac{\partial}{\partial \theta}\left(\mu \theta-A \frac{\beta}{v} \theta^{2}\right) P(\theta ; t)+\frac{1}{\Omega} \frac{1}{2} \frac{\partial^{2}}{\partial \theta^{2}}\left(\mu \theta+A \frac{\beta}{v} \theta^{2}\right) P(\theta ; t)
\end{gathered}
$$

where:

$$
\Omega=\frac{A}{v}
$$

From equation (6), the steady-state expected value $\varepsilon=\langle\theta\rangle$ of the concentration of microorganisms and the variance $\sigma=\left\langle\theta^{2}\right\rangle-\langle\theta\rangle^{2}$ are described through the time differential equations system:

$$
\begin{gathered}
\frac{d \varepsilon}{d t}=\mu \varepsilon-A \frac{\beta}{v} \varepsilon^{2} \\
\frac{d \sigma}{d t}=2\left(\mu-2 A \frac{\beta}{v} \varepsilon\right) \sigma+\frac{1}{\Omega}\left(\varepsilon \mu+A \frac{\beta}{v} \varepsilon^{2}\right)
\end{gathered}
$$

With initial conditions:

$$
\begin{aligned}
& \varepsilon(0)=\varepsilon_{0} \\
& \sigma(0)=\sigma_{0}
\end{aligned}
$$

where the probability associated with the fluctuation $\xi$ concerning the steady-state value is normal or Gaussian and is given by:

$$
P(\xi ; t)=\frac{1}{\sqrt[2]{2 \pi \sigma(t)}} \exp \left(-\frac{\xi^{2}}{2 \sigma(t)}\right)
$$

The temporal behavior of the expected value and the variance of $\theta$ is obtained from the exact analytical solution of the differential equations:

$$
\begin{gathered}
\varepsilon(t)=\frac{\alpha \varepsilon_{0} \exp (\mu t)}{\alpha+\varepsilon_{0}(\exp (\mu t)-1)} \\
\sigma=\frac{1}{\Omega} \frac{\mu^{6} \varepsilon_{0}}{\alpha^{3}}\left(2 \varepsilon_{0}^{3}-\alpha^{3}-5 \varepsilon_{0}^{3} e^{-t \mu}-3 \alpha \varepsilon_{0}^{2}\right) \\
+\frac{1}{\Omega} \frac{\mu^{6} \varepsilon_{0}}{\alpha^{3}}\left(3 \alpha^{2} \varepsilon_{0}+5 \alpha \varepsilon_{0}^{2} e^{-t \mu}+4 t \mu \varepsilon_{0}^{3}-8 t \alpha \mu \varepsilon_{0}^{2}+4 t \alpha^{2} \mu \varepsilon_{0}\right) \\
+\frac{\varepsilon_{0}^{4} e^{-2 t \mu}}{\alpha^{4}}\left(\frac{\alpha^{4}}{\varepsilon_{0}^{4}}\left(\sigma_{0}+\frac{1}{\Omega \alpha^{3}} \mu^{6} \varepsilon_{0}\left(\alpha^{3}+3 \varepsilon_{0}^{3}-2 \alpha \varepsilon_{0}^{2}-3 \alpha^{2} \varepsilon_{0}\right)\right)\right)
\end{gathered}
$$

and:

$$
\alpha=\frac{\mu v}{A \beta}=\frac{\mu a_{0} l}{A \beta}
$$

$$
\begin{gathered}
\varepsilon_{s}=\alpha \\
\sigma_{s}=\frac{1}{\Omega} \frac{\left(\varepsilon^{2}+\alpha \varepsilon\right)}{2(2 \varepsilon-\alpha)}=\frac{\alpha}{\Omega} \\
P\left(\xi_{s}\right)=\frac{1}{\sqrt[2]{2 \pi \frac{\alpha}{\Omega}}} \exp \left(-\frac{\xi^{2}}{2 \frac{\alpha}{\Omega}}\right)
\end{gathered}
$$

The behaviors predicted by the model are shown in Figures 1 and 2.

\section{B. Estimation of the behavior of the fractal dimension}

If it is considered the system steady-state to estimate the behavior of fractal dimension, it is possible to assume that the ergodicity property is fulfilled. This implies that the average values and the probability obtained by observing a specific surface site are equivalent to the probability obtained by following $\mathrm{N}$ spatial sites simultaneously (spatial averages equal to the ensemble averages). If the probability is considered from the bulk, its expected value is proportional to the density of the microorganisms in a given surface:

$$
\rho \equiv\left\langle P\left(\xi_{s}\right)\right\rangle=\frac{1}{\sqrt[2]{2 \pi \sigma}}
$$

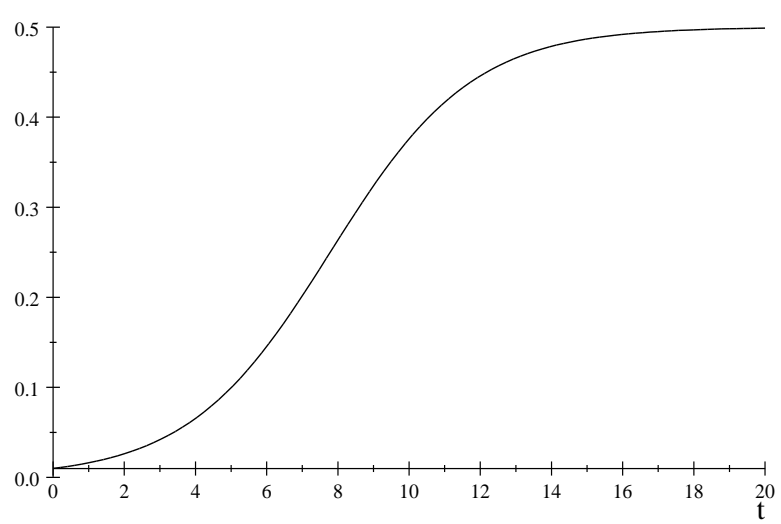

(a)

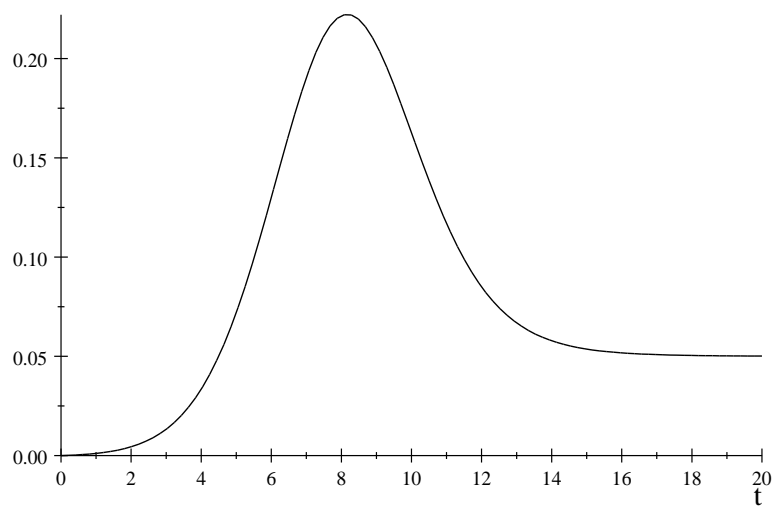

(b)

Figure 1. Predicted values of a) thickness vs. time and b) variance vs. time for $\Omega=10$ and $\alpha=0,5$.

For the steady-state: 


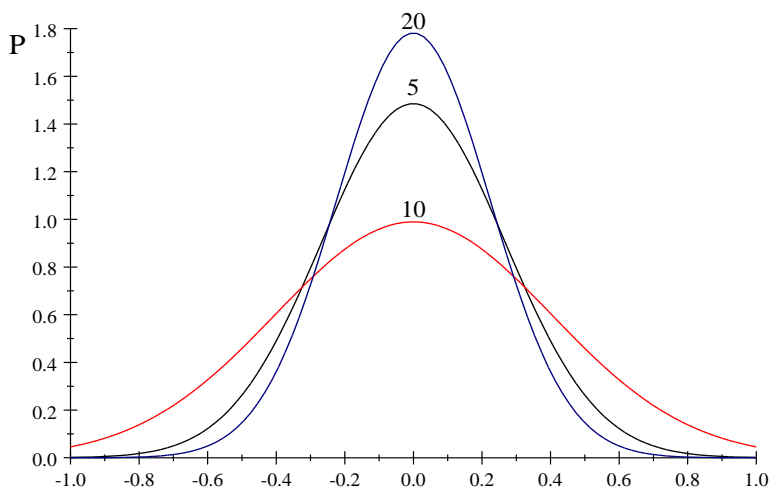

(a)

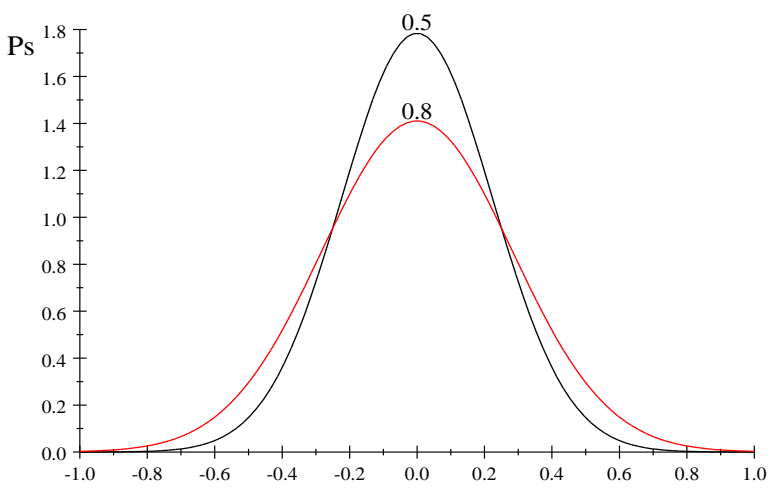

(b)

Figure 2. a) Probability function for $t=5,10,20$ and b) Stationary probability $\alpha=0.5,0.8$.

The fractal dimension is estimated in the mesoscopic scale being $\sigma$ a potential function of $\theta$, such that:

$$
\sigma_{s}=\lim _{\Omega \rightarrow \varepsilon} \frac{1}{\Omega} \frac{\left(\varepsilon^{2}+\alpha \varepsilon\right)}{2(2 \varepsilon-\alpha)} \equiv \varepsilon^{b}
$$

where:

$$
\begin{gathered}
b=\lim _{\varepsilon \rightarrow 1}\left(\frac{d\left(\ln \left(\frac{1}{\varepsilon} \frac{\left(\varepsilon^{2}+\alpha \varepsilon\right)}{2(2 \varepsilon-\alpha)}\right)\right)}{d \varepsilon}\left(\frac{d \ln \varepsilon}{d \varepsilon}\right)^{-1}\right) \\
b=-3 \frac{\alpha}{-\alpha^{2}+\alpha+2}
\end{gathered}
$$

On the other hand, it is assumed that the total area $\Phi$ occupied by microorganisms is determined by integrating the density for $\varepsilon$ :

$$
\begin{aligned}
\Phi & =\int \frac{1}{\varepsilon^{0.5 b}} d \varepsilon \\
& =C \varepsilon^{1-b}
\end{aligned}
$$

Taking into account that the fractal dimension is defined as:

$$
\Phi=C \varepsilon^{f}
$$

Is obtained:

$$
f=1+\frac{3}{2} \frac{\alpha}{\alpha(1-\alpha)+2}
$$

Substituting Equation (19) and adequately solving, the value of the average thickness of the biofilm as a function of the fractal dimension is obtained:

$$
\varepsilon_{s}=\frac{1}{2 w}\left(w+\sqrt[2]{9 w^{2}-2 w+1}-1\right)
$$

where:

$$
w=\frac{2(f-1)}{3}
$$

\section{Results and Discussion}

Figure 3 shows the "colonies" of developed fungi in samples with 6-year aging, with dark coloration; figure $3 \mathrm{a}$ is the actual picture, and Figure $3 b$ is the binary image obtained with ImageJ software. In this case, $\mathrm{f}$ is the box-counting fractal dimension. Figure 4 shows the wall surface under analysis and the Image $J$ reconstruction of a CEB after 6-years of aging where $\mathrm{x}, \mathrm{y}, \mathrm{z}$-axis are length, width, and height, respectively; units are in pixels. Figure $4 \mathrm{a}$ is the accurate picture of the surface, and Figure $4 \mathrm{~b}$ is the one obtained with the method explained before. It is possible to see height variation in space and change in uniformity due to the degradation process.

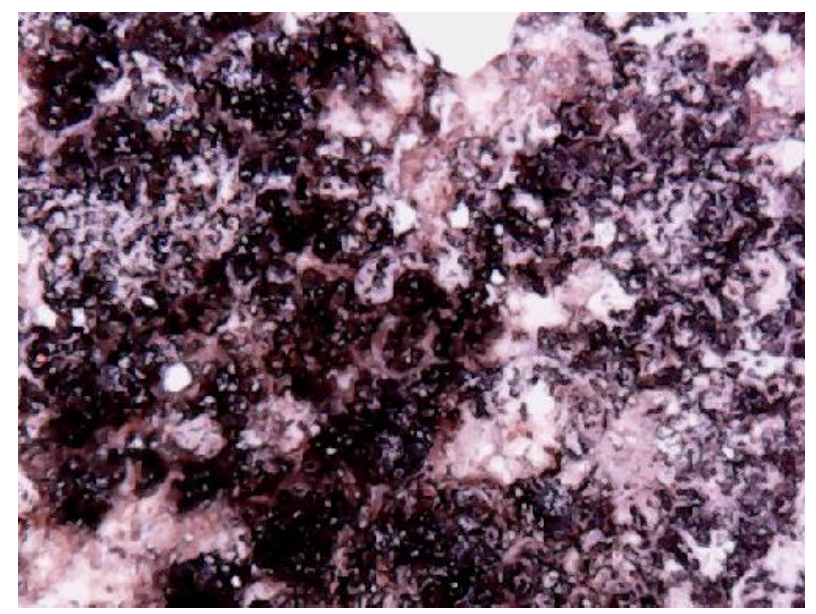

(a)

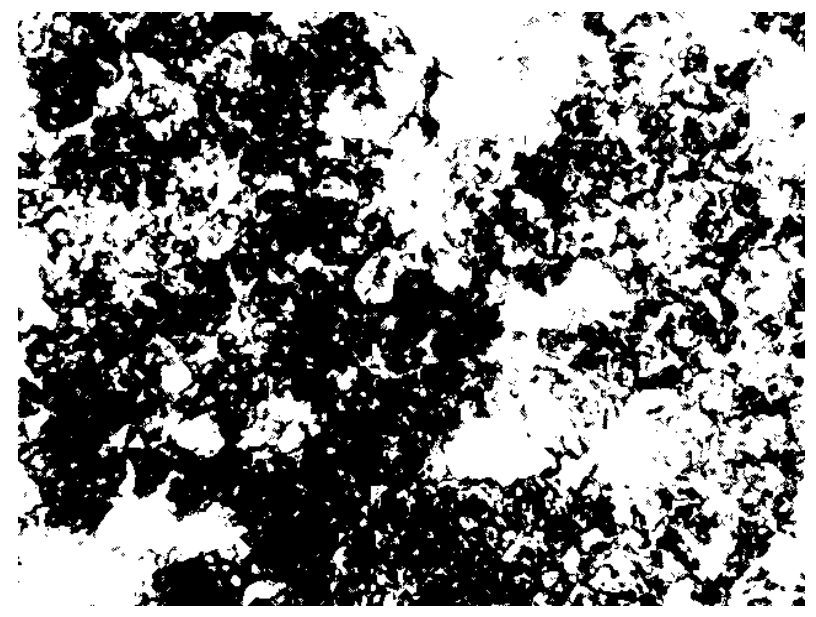

(b)

Figure 3. a) Picture of biofilm and b) corresponding binary image (l=0.6 and $\mathrm{f}=1.8375$ ). 


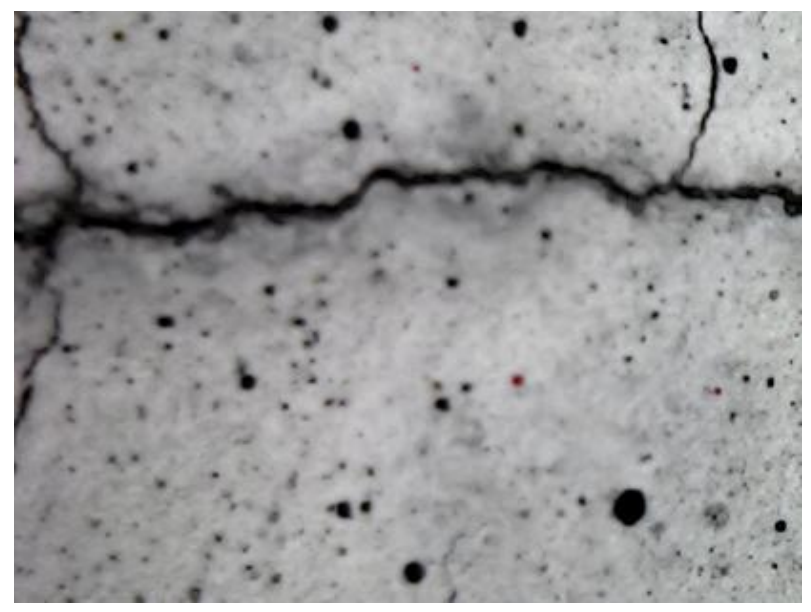

(a)

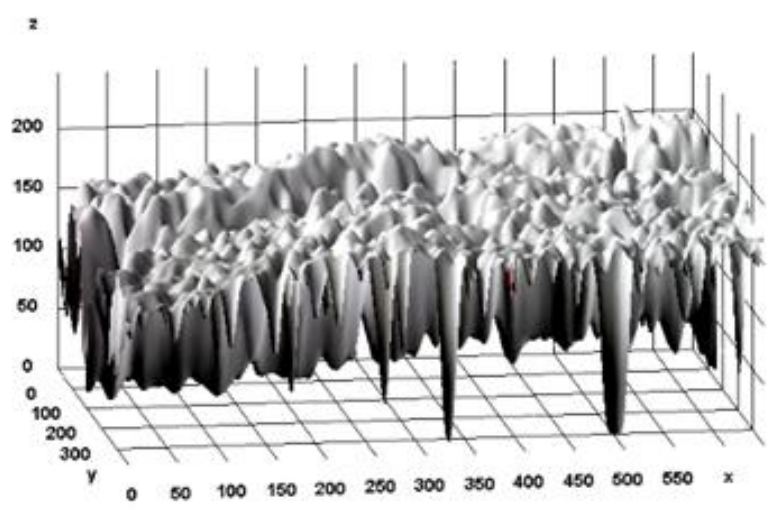

(b)

Figure 4. a) Picture of $\mathrm{CEB}$ deteriorated, and b) ImageJ surface reconstruction of the CEB after 6-years of aging.

It is important to remark that the model does not consider the presence of different species or their relationships. Second, the average intensity of pixels in the image treatment is influenced by the roughness and porosity of the surface. It also allows the first approximation of surface changes.

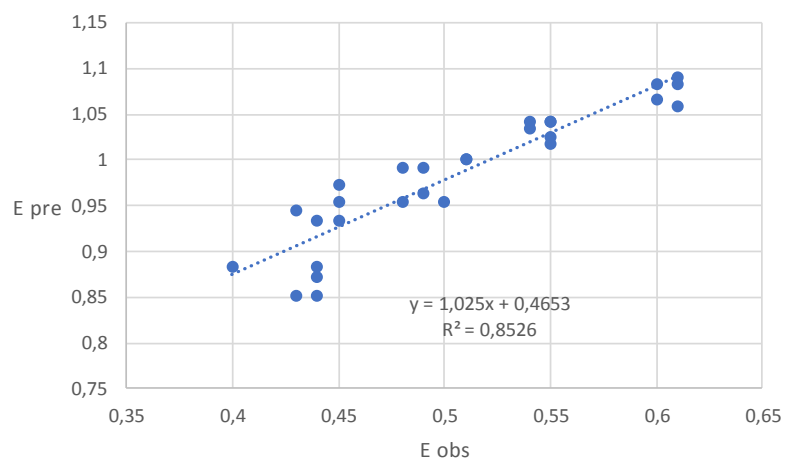

Figure 5. Comparison between the biofilm thickness values (in pixels) estimated by the proposed model and the values observed from the biofilm image treatment.
The biofilm thickness values were calculated through Equation (29) and compared with the thickness values estimated from the image treatment, equivalent to the degraded surface height. The results are shown in Figure 5 and indicate that the model is valid, where the differences between the predicted and observed values are due to two fundamental factors. A 45-degree line with a correlation factor of 0.8525 allowing reproduction of thickness by the presented equation can be seen.

Figure 6 shows the observed correlation between the biofilm thickness values determined from the intensity of the pixels and the experimental fractal dimension values considered A: exterior walls and B: interior walls without any covering. The difference is that that the outer part is exposed to the environment; hence degradation is promoted.

For this case, it is essential to note a distinct difference with and without degradation on surfaces, finding for the fractal dimension equals to 1.75 an umbral between them.

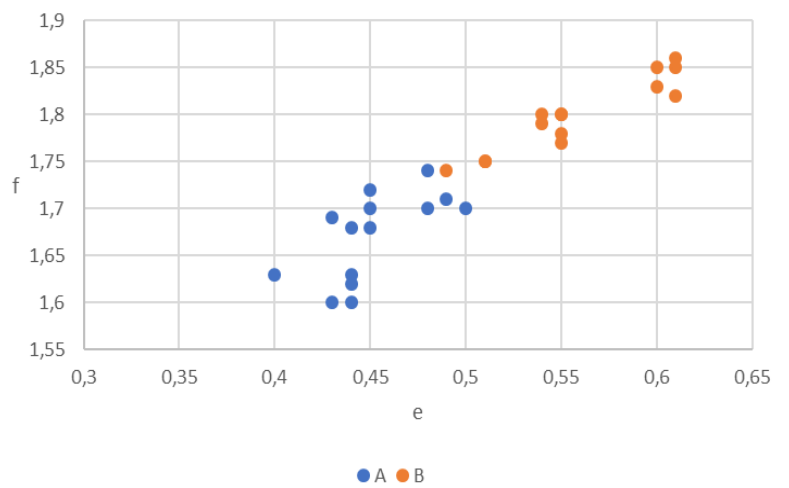

Figure 6. The biofilm thickness (e) in pixels vs. fractal dimension (f) on the outer walls A and the inner walls B.

On the other hand, for the A-group compressive strength we took 10 pieces as a representative sample of the walls, before and then of degradation, the blocks without degradation presented a value of $78.7 \pm 1.2 \mathrm{~kg}-\mathrm{cm}^{-2}$ and $49 \pm 1.2 \mathrm{~kg}-\mathrm{cm}^{-2}$ with degradation. Group B, produced with lime, showed a compression strength of $57.5 \pm 1.1 \mathrm{~kg}-\mathrm{cm}^{-2}$ and $56.8 \pm 1.1{\mathrm{~kg}-\mathrm{cm}^{-2}}^{-2}$ after six years. However, the growth of microorganisms or changes of coloration was not observed.

When using pictures analysis of surfaces, it is possible to detect how the contamination or environmental compounds can affect materials applied to, i.e., walls. Figure 7 shows the fractal dimension and the specific fractal area of a deteriorated CEB. The specific fractal area constitutes a measure of the surface roughness, which increases with the degree of deterioration until reaching a maximum value, from which it decreases. The analyzed surfaces and porosity explain this behavior, and surface fractures express a higher degree of damage. 


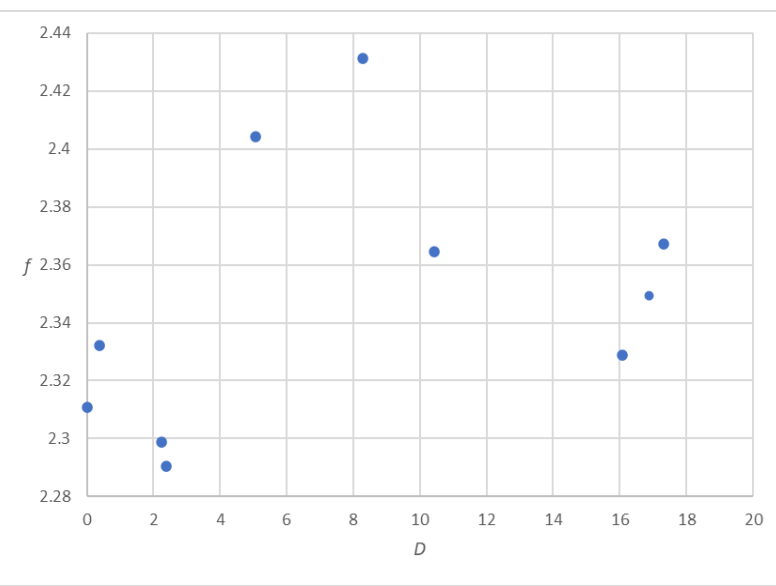

(a)

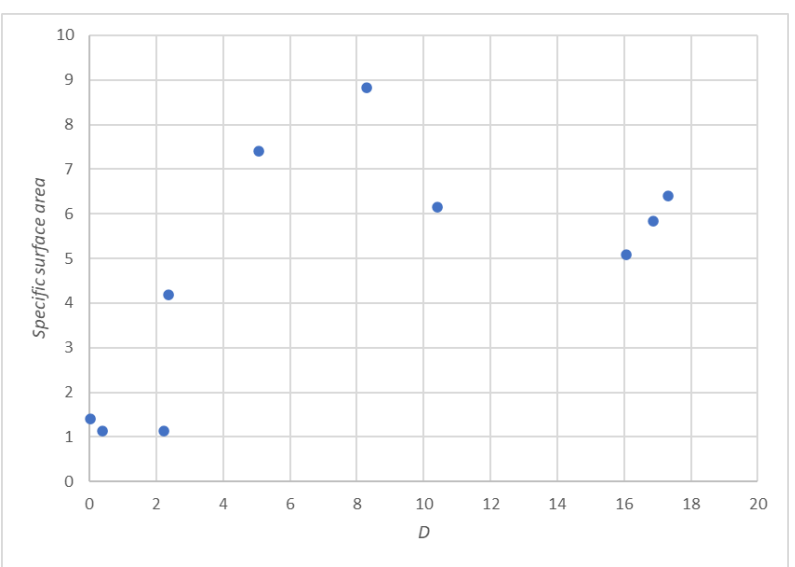

(b)

Figure 7. Deterioration extent (D-dimensionless) of a CEB vs. a) fractal dimension and b) specific surface area (dimensionless)

Although studies had been carried out to follow these processes, the solutions may present less degradation due to humidity. It is noted that only the blocks in humid environments had the growth of microorganisms (Cañola, 2019). Those generated with lime did not show this growth, probably because of the $\mathrm{pH}$ medium change. The decrease of the mechanical strength of the specimen with the presence of microorganisms can be assumed for this microbiota action since it can not only be due to moisture alone. Thus, CEBs can be modified with chemical products to avoid microbiome development $[14,15]$. Therefore, they can be improved for their structural design use, where fungal growth also occurs on traditional masonry walls $[15,16]$.

The results can be applied to the development of structural and construction materials, especially in tropical zones worldwide. Such applications will be studied in future work, extending the tests of different mechanical properties.

\section{Conclusions}

The walls of closed rooms and humid environments favor microbiota development, which can degrade the walls. Hence, it is vital to have a procedure that evaluates the degree of contamination and fungal growth of the walls. From the surface under the study's images, the average thickness of biofilm can be estimated through the model proposed. The earthen construction elements were found to present microorganisms after exposure to high moisture conditions. It was found that it did not significantly change its compression strength in cases with no biofilm growth. When fractures are predominant in the CEBs, there is a decrease in the specific surface area and the fractal dimension of the surface. Compressed earth blocks (CEB) can be added with chemical products to avoid microbiota growth without compromising their mechanical properties.

\section{Nomenclature}
$v$ volume $\mathrm{m}^{3}$
$w$ Average thickness $\mathrm{m}$
$f$ fractal dimension
$N$ Spatial Sites $\mathrm{m}$

Greek letters

$\Phi$ Total area (microorganisms) $\mathrm{m}^{2}$

$\mu$ Velocity constant (reproduction)

$\beta$ Velocity constant (death)

\section{Acknowledgments}

We want to thank PRODEP support for FIANS-UAT/2020. Project CONACYT-Problemas Nacionales 2017-5975 and PRONACES 2021 project number 315372 .

\section{REFERENCES}

[1] Nóbrega, A. C. V., \& Barbosa, N. P. "Current Developments and Future Needs for Natural Earth Construction: A State-of-the-Art". Bio-Inspired Materials, Vol 6, 2019 pp. 97-126.

[2] Aubert, J. E. "Earth construction materials: From past to modern buildings. Academic Journal of Civil Engineering" Vol. 37 No.2, 2019 pp. 217-220. https://journal.augc.asso.fr/ index.php/ajce/article/download/865/421

[3] Simons, A., Bertron, A., Aubert, J. E., Roux, C., \& Roques, C. "Characterization of the microbiome associated with in situ earthen materials". Environmental Microbiome, Vol. 15 No. 1, 2020 pp.1-11. https://doi.org/10.1186/s40793-019-0350-6

[4] Beckett, C. T. S., Jaquin, P. A., \& Morel, J. C. "Weathering the storm: A framework to assess the resistance of earthen structures to water damage". Construction and Building Materials, Vol 242, 2020 pp. 118098. https://doi.org/10.101 6/j.conbuildmat.2020.118098

[5] Simons, A., Bertron, A., Roux, C., Laborel-Préneron, A., 
Aubert, J. E., \& Roques, C. "Susceptibility of earth-based construction materials to fungal proliferation: laboratory and in situ assessment". RILEM Technical Letters, Vol 3, 2018 pp. 140-149.https://doi.org/10.21809/rilemtechlett.2018.69

[6] Gorbushina, A. A. "Life on the rocks". Environmental microbiology, Vol. 9 No. 7, 2007 pp. 1613-1631. https://doi.org/10.1111/j.1462-2920.2007.01301.x

[7] Abramova, T. T. "The Impact of Microorganisms on Monuments in the Underground Archaeological Museum of Moscow". In Processes and Phenomena on the Boundary Between Biogenic and Abiogenic Nature 2020 (pp. 639-655). Springer, Cham. https://doi.org/10.1007/978-3-030-21614-6 -34

[8] Medvey, B., \& Dobszay, G. "Durability of Stabilized Earthen Constructions: A Review". Geotechnical and Geological Engineering, 2020 pp. 1-23. https://doi.org/10.1007/s10706020-01208-6

[9] Bambang Pardoyo, Wikan Sadono Kresno, Dhimas Andra Fahreza, Tubagus Awan Maulana, "The Effect of Clay Shale Drying on the Reduction of Compressive Strength and Durability in Bawen Sub-District, Semarang Regency," Civil Engineering and Architecture, Vol. 8, No. 6, pp. 1359 - 1369, 2020. DOI: $10.13189 /$ cea.2020.080619.

[10] M.N. Uddin, V. Saraswathy, "A Comparative Study on Clay and Red Soil Based Geopolymer Mortar," Civil Engineering and Architecture, Vol. 6, No. 1, pp. 34 - 39, 2018. DOI: 10.13189/cea.2018.060104.
[11] Aranda-Jiménez, Y. G., \& Suárez-Domínguez, E. J. "Cactus stalk waterproof effect in compressed earth blocks". Nova scientia, Vol. 6 No. 11, 2014 311-323. http://www.scielo.or g.mx/scielo.php?script=sci_abstract\&pid=S2007-07052014 $000100017 \& \operatorname{lng}=\mathrm{es} \& n r m=i s o \& \operatorname{lng}=\mathrm{en}$

[12] Rueden, C. T.; Schindelin, J. \& Hiner, M. C. et al. "ImageJ2: Image J for the next generation of scientific image data", BMC Bioinformatics 18:529, 2017. PMID 29187165, doi:10.1186/s12859-017-1934-z.

[13] Van Kampen, N. G. "Stochastic processes in physics and chemistry" Vol., 1992. Elsevier.

[14] Assia, Z., Fazia, F., \& Abdelmadjid, H. "Sustainability of the stabilized earth blocs under chemicals attack's effects and environmental conditions". Construction and Building Materials, Vol. 212, 2019 pp. 787-798. https://doi.org/10.10 16/j.conbuildmat.2019.03.324

[15] Cañola, H. D., Builes-Jaramillo, A., Medina, C. A., \& González-Castañeda, G. E. "Bloques de Tierra Comprimida (BTC) con aditivos bituminosos". TecnoLógicas, Vol. 21 No. 43, 2018 pp. 135-145. https://www.redalyc.org/articulo.oa?i $d=344256704009$

[16] Preciado, A., \& Santos, J. C. "Rammed earth sustainability and durability in seismic areas as a building material". In IOP Conference Series: Earth and Environmental Science Vol. 410, No. 1, 2020, January pp. 012108. IOP Publishing. Doi:10.1088/1755-1315/410/1/012108 